\title{
Characteristics of Hydraulic Jumps over Rough Beds - An Experimental Study
}

\author{
N.G.P.B. Neluwala, K.T.S. Karunanayake, K.B.G.M. Sandaruwan and \\ K.P.P. Pathirana
}

\begin{abstract}
The present knowledge on the behaviour of hydraulic jump is only for smooth, horizontal channel beds and very limited studies have been reported in literature on the performance of hydraulic jumps on rough beds. This research attempts to investigate the characteristics of hydraulic jumps formed on rough, horizontal channel beds under different flow conditions using laboratory investigations. A series of experiments were carried out in a rectangular flume which consists of artificially roughened beds formed by placing rectangular wooden strips in specific intervals. The hydraulic parameters such as, initial water depth, sequent water depth, and flow rate were measured for different bed roughnesses. The analysis of experimental data showed that the rough bed reduces the distance to the jump from the gate and the sequent depth ratio than those on smooth beds while creating a high energy loss. With the availability of a large number of experimental data on hydraulic jumps over rough channel beds, mathematical formulations were developed to express the hydraulic jump characteristics relating roughness parameters such as; roughness density and roughness height.
\end{abstract}

Keywords: Hydraulic Jump, Rough Bed, Sequent Depth Ratio, Froude Number, Roughness Density

\section{Introduction}

Hydraulic jump is one of the most common phenomena in open channels. It is a process of transition of a supercritical flow into a subcritical flow by dissipating a large amount of energy. The hydraulic jump has attracted researchers' broad attention over many years mainly because of its importance in designing stilling basins to use as energy dissipaters.

According to the published documents, the characteristics of hydraulic jumps over smooth horizontal beds as well as over smooth sloping channel beds have been well established. However, a limited number of investigations have been reported on the characteristics of hydraulic jumps over rough horizontal beds, and their results still exist only in journal papers. Rajaratnam [14] was one of the first researchers who carried out some studies on hydraulic jumps on rough beds. Hughes and Flack [10] have done a similar study and Carollo and Pampalone [6] as well. The studies about hydraulic jumps in smooth sloping channels have been carried out by Ohtsu and Yasuda [12] and Gunal and Narayanan [9]. A brief summary of previous studies in this field is given in Section 2.2.

Most of these research studies do not produce any conclusive results and the research findings generally deviate from one research to the other. Hence, further investigations have to be carried out in this area to get a clear understanding about the characteristics of hydraulic jumps formed over rough horizontal channel beds.

In most practical applications of hydraulic jumps such as aeration, chemical mixing, energy dissipation downstream of spillways and reservoirs, flow mixing etc. occur on rough beds. But, the characteristics cannot be explained using theories developed for hydraulic jumps in smooth horizontal beds. The present study is a laboratory based research project which attempts to find out the effect of roughness on hydraulic jumps characteristics.

N.G.P.B. Neluwala, B.Sc. Eng. (Hons.)(Peradeniya), Temporary Lecturer, Department of Civil Engineering, University of Peradeniya, Sri Lanka.

K.T.S. Karunanayake, B.Sc. Eng. (Hons.)(Peradeniya), MPhil Student, Department of Civil Engineering, University of Peradeniya, Sri Lanka.

K.B.G.M. Sandaruwan, B.Sc. Eng. (Hons.)(Peradeniya), Project Engineer, Central Engineering Consultancy Bureau. Sri Lanka.

Eng.(Prof.) K.P.P. Pathirana, B.Sc. Eng. (Hons.) (Peradeniya), M.Eng., Ph.D(KULeuven)., C.Eng., FIE(Sri Lanka), MICE(London), Professor of Civil Engineering, Department of Civil Engineering, University of Peradeniya, Sri Lanka. 
The main objective of the study is to investigate the hydraulic jump characteristics on rough beds compared to hydraulic jumps on smooth beds and to develop a relationship among bed roughness and hydraulic jump parameters.

\section{Literature Review}

\subsection{Scientific Details}

For smooth horizontal beds, well established theories are present for sequent depth ratio, Energy loss etc., derived using momentum equation and continuity equation. Figure 1 shows the various parameters related to a hydraulic jump.

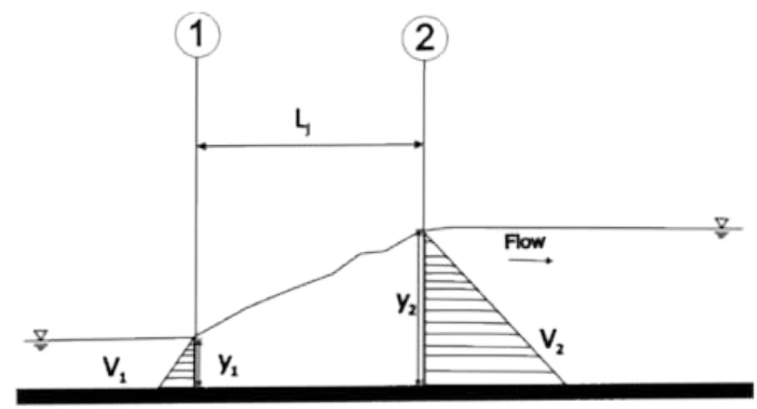

Figure 1 - Hydraulic Jump

Momentum Equation

$\frac{1}{2} y_{1}^{2}-\frac{1}{2} y_{2}^{2}=\rho q\left(v_{2}-v_{1}\right)$

where, $y_{1}$ is initial water depth and $y_{2}$ is sequent depth, $\rho$ is the density fluid and $q$ is flow rate.

Continuity Equation;

$q=y_{1} v_{1}=y_{2} v_{2} ; v_{2}=\frac{y_{1} v_{1}}{y_{2}}$

Using equations 1 and 2, it is possible to derive an equation for Sequent depth ratio and for energy loss.

$$
\frac{y_{2}}{y_{1}}=\frac{1}{2}\left(\sqrt{1+8 F r_{1}^{2}}-1\right)
$$

where, $F r_{1}$ is the upstream Froude number.

Energy loss is given by;

$$
\Delta E=\frac{\left(y_{2}-y_{1}\right)^{3}}{4 y_{1} y_{2}}
$$

\subsection{Previous Studies}

Eq. (3) has been widely used to study the hydraulic jump formed on smooth, horizontal channel beds and however, not many theories have been established for hydraulic jump characteristics on rough channel beds.

As an approach to incorporate the effect of bed roughness on hydraulic jumps, Rajarathnam [14] proposed a modification to Eq. (3) by simply adding a coefficient $(\alpha)$ to the Froude number as given in $\mathrm{Eq}$ (5).

Based on the detailed experimental investigations, Carollo and Ferro [4] suggested a value for this coefficient $(\alpha)$ which is given as 7.42 , to have a better correlation with the experimental data. However, this equation did not produce reliable results for varying bed roughnesses as the size or density if roughness elements were not directly represented in these formulations.

$$
\frac{y_{2}}{y_{1}}=\frac{1}{2}\left[-1+\sqrt{1+8 \times \alpha \times F_{1}^{2}}\right]
$$

Carollo and Ferro, [4] further improved their analysis to incorporate the size of roughness elements into Eq. (5) and accordingly, the Eq. (6) was suggested.

$$
\frac{y_{2}}{y_{1}}=\frac{1}{2}\left[-1+\sqrt{1+8 \times(1-\beta) \times F_{1}^{2}}\right]
$$

where,

$$
\beta=0.42 \times\left(\frac{t}{y_{1}}\right)
$$

where, $t$ is the roughness height.

In addition, Carollo and Ferro [6] refined their analysis on hydraulic Jumps on rough beds to have a better correlations with the experimental data and finally an improved term for $\beta$ was proposed as given below;

$$
\beta=\frac{2}{\pi} \arctan \left(0.08 \times\left(\frac{k_{s}}{h_{1}}\right)^{.75}\right)
$$

However, the various modifications made to the Eq. (3) in order to incorporate the effect of channel bed roughness on hydraulic jump characteristics have not been successful, as the spatial distribution of roughness elements is not represented in these formulations and hence, limiting their applicability. 


\section{Methodology}

\subsection{Experimental Set-up}

The experiments were carried out in the fluid laboratory of Faculty of Engineering, University of Peradeniya. A rectangular flume of $12 \mathrm{~m}$ long, $0.3 \mathrm{~m}$ wide and $0.3 \mathrm{~m}$ high was used for the experiments see (Figure 2). An overhead tank was used to get a constant flow and the flow was controlled by a control valve. The flow was confirmed to have steady flow by checking the water level before the gate. A Vnotch is attached to end of the downstream tank to measure the flow rate. Initially, it was calibrated accurately by using volumetric method. Three depth gauges were used to measure the depth of flow along the flume.

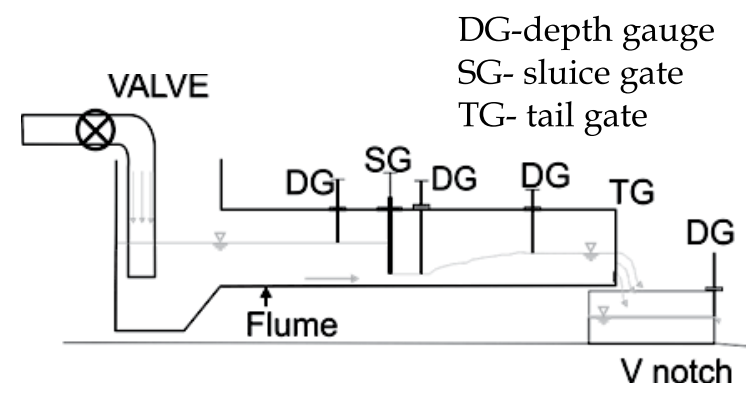

Figure 2- Schematic diagram of the experimental set-up

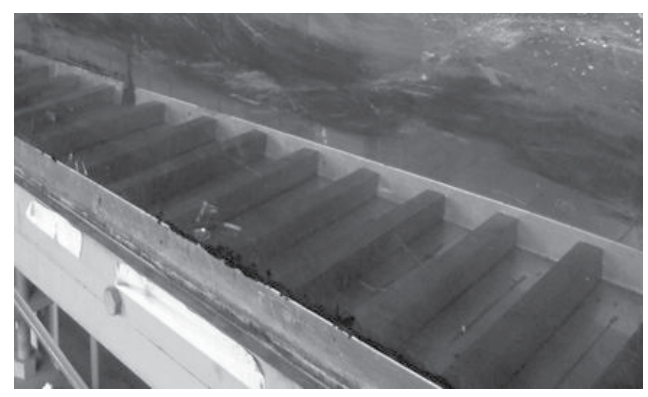

Figure 3- Roughened bed

The channel bed was roughened by fixing rectangular strips as shown in Figure 3. Three types of artificial wooden strips having sizes $(t)$ of $0.8 \mathrm{~cm}, 1.2 \mathrm{~cm}$ and $1.5 \mathrm{~cm}$ were used.

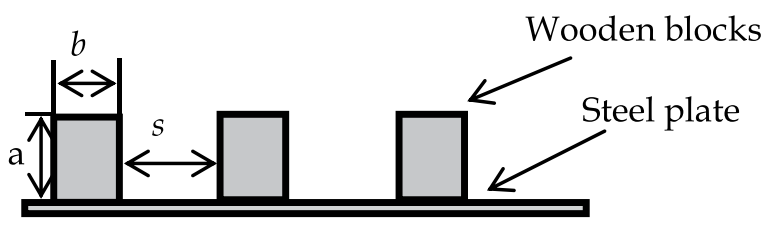

Figure 4- Arrangement of roughened bed
Where, $a$ is height of roughness elements, $b$ is width of roughness elements and $s$ is spacing between the roughness elements.

Table 1- Summary of experimental runs

\begin{tabular}{|c|c|c|c|}
\hline \multicolumn{2}{|c|}{$\begin{array}{l}\text { Experimental } \\
\text { Set-up }\end{array}$} & $\begin{array}{l}\text { Spacing of } \\
\text { roughness } \\
\text { elements / } \\
\mathrm{cm}\end{array}$ & $\begin{array}{l}\text { No. of } \\
\text { Runs }\end{array}$ \\
\hline \multicolumn{2}{|c|}{$\begin{array}{c}\text { Smooth horizontal } \\
\text { bed }\end{array}$} & - & 10 \\
\hline \multirow{3}{*}{$\begin{array}{c}\text { Rough } \\
\text { Horizontal } \\
\text { bed }\end{array}$} & $\begin{array}{c}0.8 \mathrm{~cm} \\
\text { element }\end{array}$ & $4,6,8,10$ & 40 \\
\hline & $\begin{array}{c}1.2 \mathrm{~cm} \\
\text { element }\end{array}$ & $4,6,8,10$ & 40 \\
\hline & $\begin{array}{c}1.5 \mathrm{~cm} \\
\text { element }\end{array}$ & $4,5,6,8,10$ & 50 \\
\hline
\end{tabular}

\subsection{Procedure}

The experiments were carried out in two stages, test runs on the smooth horizontal bed are covered in stage 1 whereas, the runs on rough beds in stage 2 . For investigating hydraulic jump characteristics on smooth horizontal bed, the bed was levelled and the bed readings were taken using the depth gauges. After opening the control valve, the sluice gate was adjusted to achieve a still water column at upstream of the sluice gate while trying to obtain a hydraulic jump in downstream side. In this situation, the Initial depth $\left(y_{1}\right)$, sequent depth $\left(y_{2}\right)$, length of jump, size of the gate opening and the flow rate were measured. During this study, ten experimental runs were conducted on smooth horizontal channel bed by varying the flow rates, ranging from 8 to $25 \mathrm{l} / \mathrm{s}$.

The same procedure was repeated for the experiments with rough channel beds. In order to make the channel bed rough, the one type of roughness elements was fixed on the aluminium bed in specific intervals starting near the sluice gate as given in Table 1 . (Normally investigations were begun with $4 \mathrm{~cm}$ spacing of roughness elements). For each roughness element and spacing, 10 experimental runs were carried out by varying the flow rates. In each experimental run initial depth, sequent depth and flow rates were measured. The above procedure was repeated for five different spacing arrangements and for 3 different types of elements. Altogether 140 experimental runs were conducted for rough channel beds covering the flow rates from 8 to $25 \mathrm{l} / \mathrm{s}$. 


\section{Results and Discussion}

The results obtained under two stages of experimental runs are presented in the following Sections.

\subsection{Smooth horizontal bed}

Table 2 shows the results obtained for the test runs carried out on smooth channel bed. As theoretical equations are available for hydraulic jump characteristics on smooth channel beds, the experimental data of $\left(y_{2} / y_{1}\right)$ were compared with the theoretical values as presented in Figure 5. In Figure 5, a smaller reduction in the sequent depth ratio could be observed when compared to theoretical values which could be due to the minor roughness present in the aluminium bed as well as the experimental errors.

Table 2 - Observed data for Smooth bed

\begin{tabular}{|c|l|l|l|c|}
\hline $\begin{array}{l}\text { Trial } \\
\text { No }\end{array}$ & $\mathbf{y}_{\mathbf{1}} / \mathbf{( m )}$ & $\mathbf{y}_{\mathbf{2}} / \mathbf{( m )}$ & $\mathbf{Q} /(\mathbf{l} / \mathbf{s})$ & $\begin{array}{l}\mathbf{y}_{2} / \mathbf{y}_{\mathbf{1}} \\
\text { Observed }\end{array}$ \\
\hline 1 & 0.013 & 0.092 & 7.46 & 7.076 \\
\hline 2 & 0.014 & 0.093 & 9.11 & 6.744 \\
\hline 3 & 0.017 & 0.103 & 10.62 & 6.203 \\
\hline 4 & 0.024 & 0.128 & 16.09 & 5.362 \\
\hline 5 & 0.029 & 0.129 & 18.81 & 4.384 \\
\hline 6 & 0.034 & 0.135 & 20.60 & 3.973 \\
\hline 7 & 0.038 & 0.150 & 26.27 & 3.920 \\
\hline 8 & 0.018 & 0.109 & 11.26 & 5.962 \\
\hline
\end{tabular}

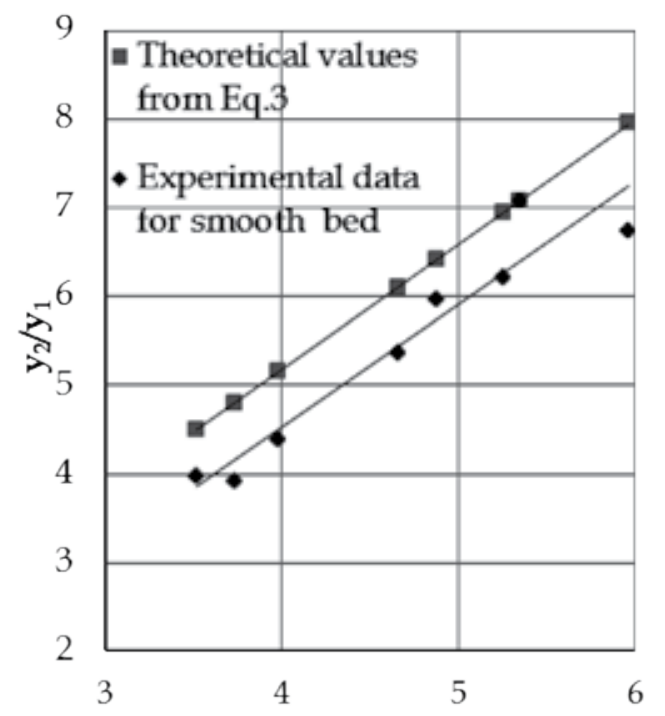

Figure 5- $y_{2} / y_{1}$ versus Froude Number

\subsection{Rough horizontal bed}

The result for $0.8 \mathrm{~cm}$ elements with $4 \mathrm{~cm}$ interval is shown in Table 3. From Figure 6, it could be observed that the sequent depth ratio was directly proportional to the Froude number in each case of different spacing. Therefore, to predict the observed data, it required to identify the parameters that were affected due to changes in specific roughness and their spacing.

Table 3 - Observed data for $0.8 \mathrm{~cm}$ elements with $4 \mathrm{~cm}$ interval

\begin{tabular}{|c|c|c|c|c|c|}
\hline $\begin{array}{l}\text { Spacin } \\
\text { g } \\
/ \mathbf{c m}\end{array}$ & $\begin{array}{l}\text { Elem } \\
\text { ent } \\
\text { size/ } \\
\mathbf{c m}\end{array}$ & $\mathbf{y} \mathbf{1} / \mathbf{m}$ & $\mathbf{y} \mathbf{y} / \mathbf{m}$ & $\begin{array}{l}\text { weir } \\
/ \mathbf{m}\end{array}$ & $\begin{array}{l}\mathbf{Q} / \\
\mathbf{( 1 / s )}\end{array}$ \\
\hline 4.0 & 0.8 & 0.03 & 0.10 & 0.16 & 15.30 \\
\hline 4.0 & 0.8 & 0.03 & 0.11 & 0.17 & 17.17 \\
\hline 4.0 & 0.8 & 0.03 & 0.11 & 0.17 & 18.57 \\
\hline 4.0 & 0.8 & 0.03 & 0.12 & 0.18 & 20.43 \\
\hline 4.0 & 0.8 & 0.03 & 0.12 & 0.18 & 21.62 \\
\hline 4.0 & 0.8 & 0.04 & 0.12 & 0.19 & 22.96 \\
\hline 4.0 & 0.8 & 0.04 & 0.12 & 0.19 & 23.55 \\
\hline 4.0 & 0.8 & 0.04 & 0.12 & 0.19 & 24.11 \\
\hline 4.0 & 0.8 & 0.04 & 0.12 & 0.19 & 24.81 \\
\hline 4.0 & 0.8 & 0.04 & 0.13 & 0.19 & 24.88 \\
\hline 4.0 & 0.8 & 0.04 & 0.13 & 0.19 & 25.23 \\
\hline 4.0 & 0.8 & 0.04 & 0.13 & 0.19 & 25.86 \\
\hline
\end{tabular}

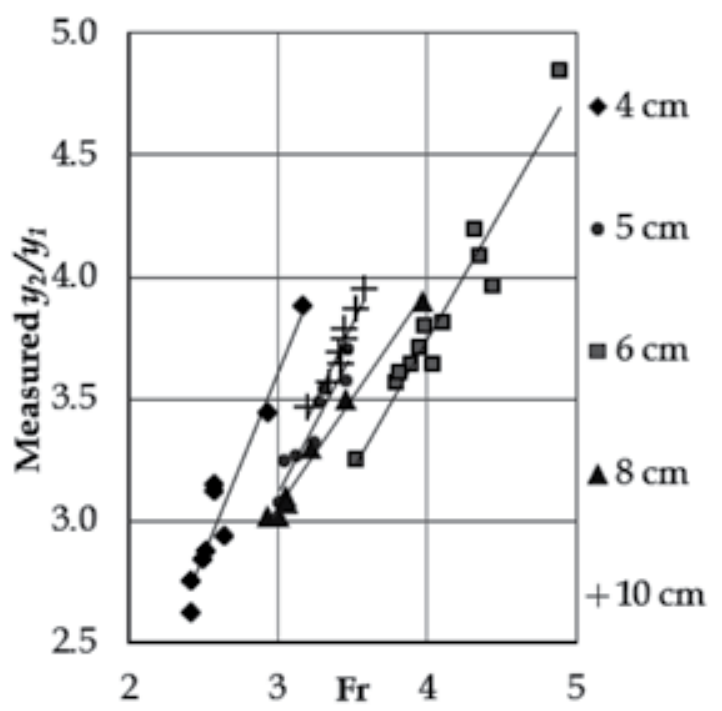

Figure 6- Measured $y_{2} / y_{1}$ versus $\mathrm{Fr}$ for 1.5 roughness elements for different spacing

Figure 7 shows a comparison between computed $y_{2} / y_{1}$ using equations suggested by different researchers and observed $y_{2} / y_{1}$. It can be seen from the figure that the existing 
formulations derived for hydraulic jumps on rough beds were not in agreement with the observed data.

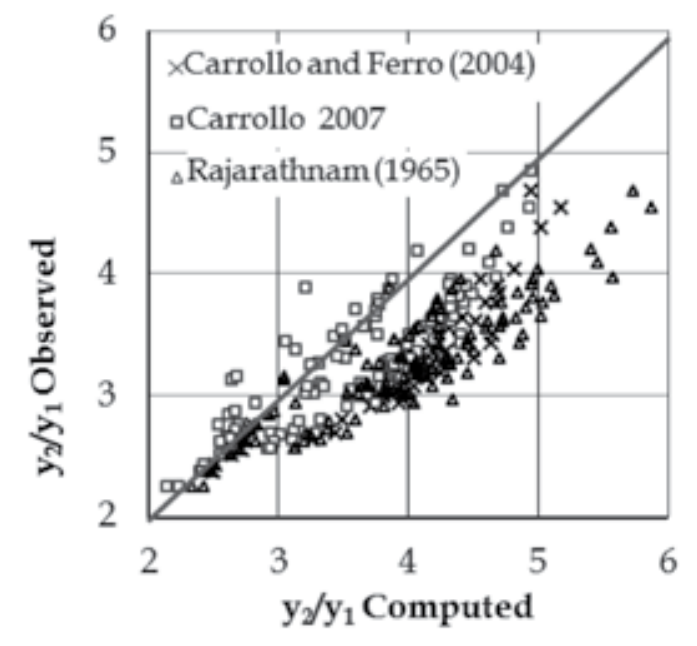

Figure $7-y_{2} / y_{1}$ observed vs. $y_{2} / y_{1}$ computed

To develop a proper relationship a detailed data analysis had to be carried out and useful result could be developed as presented in Section 5 .

\section{Data analysis}

Analysis of data to form theoretical equations was carried out to develop relationships among governing hydraulic jump characteristics. For that a dimensional analysis was first carried out and then the experimental results were analysed accordingly.

\subsection{Dimensional Analysis}

The parameters that affect the characteristics of the hydraulics jump can be identified as;

$\left(y_{1}, V, g, v, t, s\right)$

where $t=$ Height of roughness elements $\mathrm{v}=$ Kinematic viscosity of the fluid, $V=$ Velocity at the upstream side of the hydraulic jump and $s=$ spacing of roughness elements.

Hence, from the dimensional analysis using Buckingham's pi theorem, the sequent depth ratio was found to be related to other parameters as follows;

$$
\frac{y_{2}}{y_{1}}=f_{2}\left(F r=\frac{v_{1}}{g \times y_{1}}, \operatorname{Re}=\frac{v_{1} \times y_{1}}{v}, \frac{t}{y_{1}}, \frac{s}{y_{1}}\right)
$$

For higher values of Re no, viscous effect can be neglected and hence, the above equation can be simplified as,

$$
\frac{y_{1}}{\mathrm{y}_{2}}=\mathrm{f}_{2}\left(F r, \frac{t}{y_{1}}, \frac{s}{y_{1}}\right)
$$

The parameters such as Sequent depth ratio $\left(y_{2} / y_{1}\right)$, Froude number, Energy loss, and Jump efficiency were calculated and plotted in nondimensional form to observe the relationship with the bed roughness.

As shown in Section 4, most of the previous researchers were unable to develop a unique relationship to relate hydraulic jump parameters with bed roughness. With the results of the dimensional analysis, it was observed that the main drawback of the available formulations as the lack of a term representing the roughness density, as most of these equations were developed using experimental studies with only one type of roughness spacing. Therefore, a new parameter called 'roughness density' $(d=$ width of roughness element /Spacing) was incorporated into the analysis to represent the roughness spacing.

This relationship was confirmed to be accurate as the graph plotted, $y_{2} / y_{1} \times(1-(|0.23-d|))$ versus Froude number behaved in a linear manner giving a regression coefficient of 0.93 . The equation 10 was derived using the graph to relate the above parameters.

$$
\frac{y_{2}}{y_{1}}=\frac{(0.8568 \mathrm{Fr}+0.3378)}{(1-|0.23-\mathrm{d}|)}
$$

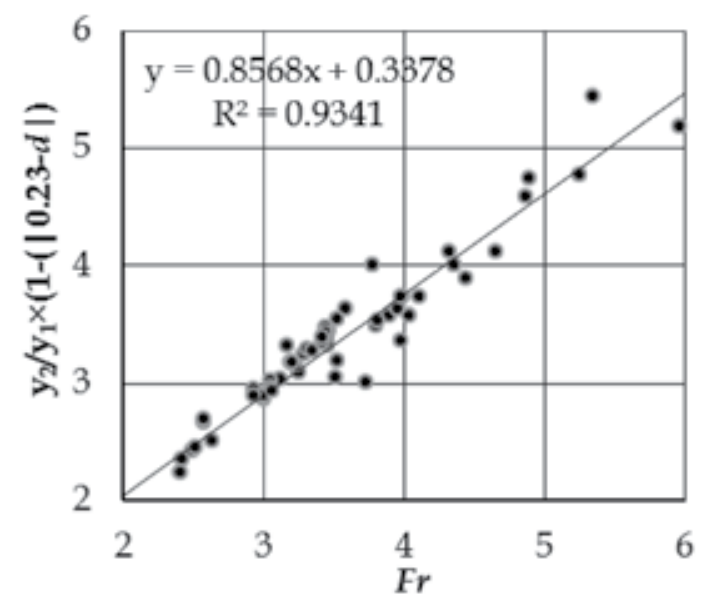

Figure 8- Relationship of $d$ for $1.5 \mathrm{~cm}$

$$
\text { roughness element }
$$

However the Eq. 10 does not include a term to relate roughness height $(t)$. By examining the equations developed by Carollo (2007) and Rajarathnam (1956) and considering the results 
from dimensional analysis a term $\left(t / y_{1}\right)$ was introduced to Eq. 10 to relate the roughness height. As a result equation 11 was obtained.

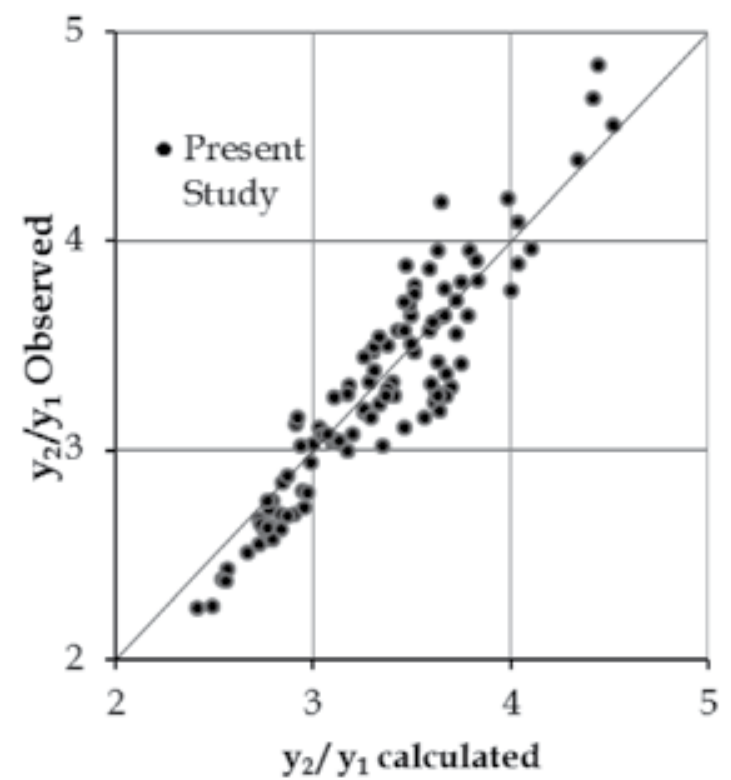

Figure 9- Prediction of $y_{2} / y_{1}$ for all the results using Eq. 11

$$
\frac{y_{2}}{y_{1}}=\frac{0.8568\left(1-0.05 \times \frac{t}{y_{1}}\right) \times F r+0.3378}{1-|0.23-d|}
$$

The Equation 11 provides a better correlation between hydraulic jump characteristics and properties of roughened bed for all the experimental data collected see Figure 9.

\section{Summary and Conclusions}

The objective of this study was to identify the characteristics of hydraulic jumps on rough channel beds, and several experiments were carried out and various relationships were developed between the hydraulic jumps parameters.

To achieve the above goal, 140 experimental runs were carried out for various roughness beds for a range of flow rate 10-25 l/s while changing the roughness density ( $8 \%$ to $37.5 \%$ ) and the element sizes $(0.8 \mathrm{~cm}$ to $1.5 \mathrm{~cm})$.

The parameters such as Sequent depth ratio, Froude number, Energy loss and Jump efficiency were calculated and they were plotted in dimensionless form. By analysing the experimental data several relationships were developed.
The graphs of Sequent depth ratio versus Froude number indicated almost a linear relationship between the two parameters as described in the Section 4 (For smooth theoretical equation $\mathrm{Y}=1.4051 \times \mathrm{X}-0.4421, \mathrm{R}^{2}=$ 1 ). For the smooth aluminium bed the sequent depth ratio decreases in $10 \%$ which could be due to the minor roughness present in the aluminium bed as well as the experimental errors.

For artificially roughened bed, it was found that the jump characteristics were a function of Froude number, roughness height and roughness density. It was found that maximum effect of roughness elements occurred at a roughness density of 0.23 . At this stage the sequent depth ratio reduced up to $34 \%$. A new theoretical equation was developed to relate the above parameters to sequent depth ratio of hydraulic jumps on rough beds. Hence, this research outcome would lead to develop the knowledge required to analysis practical applications on hydraulic jumps. Further studies can be carried out in uniformly roughened bed which is ideal to natural river beds and irrigation channels.

\section{References}

1. Chow, V. T., Open Channel Hydraulics, McGraw-Hill, United states, 1959.

2. French, R. H., Open Channel Hydraulics, McGraw-Hill, United States, 1986.

3. Abbaspour, A., Dalir, A., Farsadizadeh, D., \& Sadraddini, A., "Effect of Sinusoidal Corrugated Bed on Hydraulic Jump Characteristics", Journal of Hydro-Environment Research, Vol. 3, No. 2, pp. 109-117, 2009.

4. Bejestan, M., \& Neisi, K., “A New Roughened Bed Hydraulic Jump Stilling Basin", Asian Journal of Applied Sciences, Vol. 2, No. 2, pp. 436-445, 2009.

5. Belcher, B. J., \& Fox, J., “Outer Scaling for Open Channel Flow over a Gravel Bed", Journal of Engineering Mechanics, Vol. 137, No. ,pp. 40-46, 2011.dd.

6. Carollo F.G., Ferro V., "Determination of Conjugated Heights Emphasis on Free Smooth Surface and Rough", Journal of Agricultural Engineering, Vol. 4, pp. 1-12. 2004.

7. Carollo, F.G., Ferro,V. and Pampalone, V., "Hydraulic Jumps on Rough Beds", Journal of 
Hydraulic Engineering, Vol. 133, No. 9, pp. 989-999, 2007.

8. Ead, S., \& Rajaratnam, N., "Hydraulic Jumps on Corrugated Beds", Journal of Hydraulic Engineering, Vol. 128, No. 7, pp. 656-663, 2002.

9. Elsebaie, I. H., \& Shabayek, S., "Formation of Hydraulic Jumps on corrugated Beds", International Journal of Civil \& Environmental Engineering, Vol. 10 No. 01, pp. 40-50, 2010.

10. Gunal, M., \& Narayanan, R., "Hydraulic Jumps in Slopping Channels", Journal of Hydraulic engineering , Vol. 122, No. 8, pp. 436454, 1996.

11. Hughes, W. C., \& Flack, J., “Hydraulic Jump properties Over a Rough Bed", Journal of Hydraulic Engineering, Vol. 110, No.12, pp. 1755-1771, 1984.

12. Nikmehr, S., \& Tabebordbar, A., "Hydraulic Jumps on Adverse Slope in Two Cases of Rough and Smooth Bed", Research Journal of Applied Sciences, Engineering and Technology Vol. 2, No. 2, pp. 19-22, 2010.

13. Ohtsu, I., Yasuda, Y., "Hydraulic Jump in Sloping Channels", Journal of Hydraulic Engineering, Vol. 117, No. 7, pp. 905-921, 1991.

14. Pagliara, S., Lotti, I., \& Palermo, M., "Hydraulic jump on rough bed of stream rehabilitation structures", Journal of Hydroenvironment Research,Vol. 2, No. 1, pp. 29-38, 2008.

15. Rajaratnam, N., "Hydraulic jumps on rough beds", Trans. Eng. Inst. Canada, Vol. 11, pp. 18,1968 .

16. Willium, C. H, Flack, J.E., “Hydraulic jump properties over a rough bed", Journal of Hydraulic engineering, Vol 110, No. 2 , pp. 1755$1771,1984$. 